\title{
BMJ Open Risk factors associated with current intimate partner violence at individual and relationship levels: a cross-sectional study among married rural migrant women in Shanghai, China
}

\author{
Xiaowen Tu, ${ }^{1,2}$ Chaohua Lou ${ }^{1,2}$
}

To cite: Tu X, Lou C. Risk factors associated with current intimate partner violence at individual and relationship levels: a cross-sectional study among married rural migrant women in Shanghai, China. BMJ Open 2017;7:e012264. doi:10.1136/ bmjopen-2016-012264

- Prepublication history and additional material is available. To view please visit the journal (http://dx.doi.org/10.1136/ bmjopen-2016-012264)

Received 13 April 2016 Revised 23 February 2017 Accepted 6 March 2017

CrossMark

${ }^{1}$ Shanghai Institute of Planned Parenthood Research, Shanghai, China

${ }^{2}$ Key Laboratory of Reproduction Regulation of NPFPC (SIPPR,

IRD, Fudan University),

Shanghai, China

Correspondence to

Dr Xiaowen Tu;

tuxwcn@163.com

\section{ABSTRACT}

Objective To identify individual and relationship risk factors associated with current intimate partner violence (IPV) against married rural migrant women in Shanghai, China.

Design Cross-sectional survey.

Setting Two subdistricts of one administrative district, Shanghai, China.

Participants A total of 958 married rural migrant women of reproductive age were selected using a communitybased two-stage cluster sampling method in April and May of 2010.

Outcome measures Data were collected using a modified questionnaire based on an instrument from the WHO Multi-country Study on Women's Health and Domestic Violence against Women. Adjusted odds ratio (AOR) and $95 \% \mathrm{Cl}$ from a multivariable logistic regression model were estimated to identify individual and relationship risk factors associated with different types of violence in the past 12 months.

Results Women's low financial autonomy was associated with all types of violence (AORs ranged from 1.98 to 7.89, $\mathrm{p}<0.05)$. Quarrelling with husband was a very strong risk factor (AORs $>6, p<0.05$ ) for both emotional violence and any violence. Experience of job change in the past year (AOR=4.03, 95\% $\mathrm{Cl} 1.57$ to 10.35) and history of husband being abused ( $\mathrm{AOR}=4.67,95 \% \mathrm{Cl} 2.17$ to 7.69 ) were strongly associated with physical or sexual violence. Conclusion Women's low financial autonomy and unstable employment status at an individual level, quarrelling with husband and history of husband beaten by family members at a relationship level were identified as the most robust risk factors for IPV among married rural migrant women. Efforts to prevent IPV among this population should be made to involve both women and their husbands, with a focus on improving financial autonomy and employment status of women, promoting problem-solving and interaction skills of the couples and changing their knowledge and attitudes towards gender norms and IPV.

\section{INTRODUCTION}

Intimate partner violence (IPV) against women is the most common form of violence
Strengths and limitations of this study

- Study method was adopted from the WHO Multicountry Study on Women's Health and Domestic Violence against Women to measure intimate partner violence (IPV) and related factors, which enables international comparability and ensures high quality of data.

- The modified study method also minimised the under-reporting of IPV, which is generally considered an embarrassing private matter in China.

- The self-reported family economic status was not associated with IPV owing to lack of variation in the studied population.

- This study has insufficient statistical power to investigate other potential risk factors (eg, partner's behaviours) in association with IPV due to small sample size.

- As a cross-sectional study, this study could provide evidence only for associations but not for causality.

experienced by women worldwide. ${ }^{1-4}$ It is a human rights issue and also a serious public health problem with long-term consequences for women, their children, community and society. Prevention of IPV will protect the physical, mental and economic well-being and development of women, families, communities and societies as a whole. ${ }^{4}$

Understanding the status quo and risk factors of IPV is crucial for developing intervention programmes to effectively reduce violence against women. Numerous studies have identified risk factors associated with IPV at individual, relationship, community and societal levels as shown by the ecological model in figure $1 .^{2-5}$ However, few studies have been conducted to investigate IPV risk factors in China. Findings from other countries may not be applicable in China due to differences in politics, economies, cultures, ecologies and histories. 


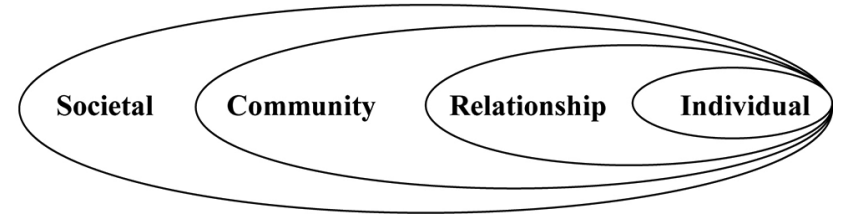

Figure 1 The ecological model for understanding intimate partner violence.

Violence against a woman by her husband is traditionally considered as a family matter in China, which is largely overlooked and ignored. IPV has received more and more attention in China since the International Conference on Population and Development in Cairo in 1994 and the Fourth World Conference on Women in Beijing in 1995. Physical abuse was not an acceptable ground for divorce in mainland China until 2001 when the marriage law was amended to explicitly ban domestic violence. A national population-based survey found that $34 \%$ of women aged 20-64 years with a spouse or a steady partner experienced physical violence, and the prevalence varied substantially between urban and rural areas and by regions in 1999-2000. ${ }^{6}$ One multi-country study conducted by the United Nations reported a prevalence of $51.6 \%$ physical and/or sexual IPV in the surveyed sites of China. ${ }^{3}$ Studies conducted in Hong Kong showed that the prevalence of physical violence among Chinese women ranged from $8.5 \%$ to $18 \%$ in the lifetime period and $4.1 \%$ to $15.5 \%$ in the preceding year. ${ }^{78}$ Some risk factors for IPV in China were similar to those reported in other countries, such as low education, low socioeconomic status, alcohol use, frequent quarrelling with husband, acceptance of violence and exposure to violence during childhood. ${ }^{36-11}$ However, no studies to date have investigated the IPV risk factors among a vulnerable population such as internal rural-to-urban migrants (hereafter referred as 'rural migrants') in China.

The number of rural migrants who are former peasants or farmers has been increasing since the mid-1980s in China owing to socioeconomic development and urbanisation of the economic reform started in 1978. Rural migrants are becoming a huge part of the urban labour force according to the National Bureau of Statistics. Most of the 253 million migrants in China by the end of 2014 were rural migrants who went to cities to open small businesses or provide cheap labour in the hope of higher pay and a better life. ${ }^{12}$ Rural migrants were young (33.7 years old on average), lived in poor housing conditions and the majority had a junior secondary education. ${ }^{13}$ In comparison with their urban counterparts, rural migrants had lower education levels and fewer skills. They were three times less likely to have senior secondary school or higher education than urban permanents $(13.3 \%$ vs $44.1 \%$ ) based on the 2000 census. ${ }^{14}$ Rural migrants also face considerable insecurity in employment, income, social welfare and access to education resources for their children under the household registration system (Hukou) established in the 1950s to classify households as rural (agricultural) or urban (non-agricultural)..$^{15-17}$ It is extremely difficult to change a Hukou from rural to urban owing to its linkage to the registration status of social welfare and employment. People with an urban Hukou are entitled to employment, healthcare, housing, pension and food subsidies in China, which are not available to people with a rural Hukou. Rural migrants only have temporary residence permit and labour contracts protection. ${ }^{18}$ Many rural migrants are engaged in physically demanding, low-paying, and low-skilled temporary jobs in the manufacturing, construction, commerce and service industries owing to the Hukou limitation. ${ }^{16}{ }^{17}$ Most rural migrants are unable to move up to higher positions in urban industries until they have permanent urban residence permit (urban Hukou). ${ }^{19}$

Little is known about IPV in rural migrants despite their vulnerability to IPV. To fill this gap, we conducted a study to investigate IPV against women and its association with a range of health outcomes among married rural migrant women of reproductive age (15 49 years) in Shanghai, China. Findings on prevalence and health outcomes of IPV have been published elsewhere. ${ }^{20}{ }^{21}$ This paper examines risk factors associated with different types of IPV against married rural migrant women, including individual factors on demographic and socioeconomic characteristics, financial autonomy and personal history, as well as relationship factors related to husband, relatives and neighbours.

\section{METHOD}

\section{Study design and subjects}

Data were drawn from a cross-sectional survey conducted among married rural migrant women of reproductive age in April and May of 2010 in Shanghai, China's largest city with nearly 9 million migrants, who have stayed in the city for more than 6 months. ${ }^{22}$ Eligible subjects are married women aged 20-49 years old (the legal marriage age in China is $\geq 20$ years for women) living together with their husband and the couple had stayed in the city for $>6$ months but did not have a Shanghai Hukou or permanent residence permit. Women older than 49 years and unmarried women were excluded because women of this age were not registered in the computerised system of the local population and family planning department and cohabitation before marriage in China is very low $(0.2 \%$ based on the China Family Development Report $2015^{23}$ ).

Shanghai has 17 administrative districts and one county. Subjects were selected through a community-based two-stage cluster sampling method. First, two subdistricts were randomly selected from one district with an average socioeconomic development level of Shanghai to generate a sample representing the socioeconomic status of the study population. Second, residential areas were randomly selected from each subdistrict with a selection probability proportional to the number of married migrant women living in the residential community. Ten and 16 residential areas were respectively selected 
from the two subdistricts to split the study sample size equally between the subdistricts. This study recruited all eligible subjects living in the selected residential areas. For households with more than one eligible subject, one woman was randomly selected for safety and confidentiality reasons. The final study sample comprised 958 women, representing $99.7 \%$ of eligible women. All study participants were fully informed about, and consented to, the survey.

Trained female interviewers completed a face-to-face interview with each study participant using a modified questionnaire based on an instrument from the World Health Organization (WHO) Multi-country Study on Women's Health and Domestic Violence against Women. ${ }^{24}$ The questionnaire was pilot tested before the main data collection. All questions about violence were phrased and asked in a supportive and non-judgemental manner. To ensure consistent data collection, interviewers were uniformly trained on methodological issues with special emphasis on introduction of IPV, gender and gender inequality, skills in dealing with sensitive issues, concerns of confidentiality, ethics and safety, and knowledge and skills to provide counselling to interviewees. To protect the safety of participants and the research team and to improve the quality of the data, the survey followed the WHO ethical and safety guidelines for research on violence against women. ${ }^{25}$ The study was framed as research into women's reproductive health to enable participants to explain the survey safely to others. The interview was anonymous and was conducted in a private room outside the participant's home. Before the end of each interview, the interviewer told each IPV victim that "no one has the right to treat someone else in that way' and provided them with the necessary information for referral. The study and the procedures were approved by the institutional review board of Shanghai Institute of Planned Parenthood Research, Shanghai, China.

\section{Measures}

IPV is defined as any act of emotional, physical or sexual abuse by a current or former husband (figure 2). Questions about IPV over the lifetime of the marriage and in the past year were asked separately. Participants were grouped based on their experiences (yes or no) in the defined period of time. As violence over the married lifetime might have occurred before and after women's migration to Shanghai, this study focused on IPV in the past year.

Self-report risk factors for IPV include demographic and socioeconomic characteristics, personal history and factors related to husband, family members, relatives and neighbours. Women's financial autonomy was measured by a sum score based on their answers to six questions presented in table 1 . The higher the sum score, the lower the financial autonomy. Definitions and categorisations of other risk factors are shown in tables 2-3.

\section{Emotional violence by a husband}

$>$ was insulted or made to feel bad about herself

$>$ was belittled or humiliated in front of others

$>$ husband had done things to scare or intimidate her on purpose

$>$ husband had threatened to hurt her or someone she cared about

$>$ husband had threatened to separate her from her children

\section{Physical violence by a husband}

$>$ was slapped or thrown something that could hurt her

$>$ was pushed, shoved or dragged

$>$ was hit with a fist or kicked

$>$ was choked or burnt on purpose

$>$ was threatened or attacked with a knife or other weapon

\section{Sexual violence by a husband}

$>$ was coerced to perform sexual acts that she found degrading or humiliating

$>$ was physically forced into sexual intercourse when she did not want

$>$ had sexual intercourse when she did not want to because she was afraid of what husband might do

Figure 2 Operational definition of intimate partner violence.

\section{Data analysis}

IPV was dichotomised in the analysis as the dependent variable, including emotional violence, physical or sexual violence (defined as one or more acts of physical or sexual violence in combination) and any violence (defined as one or more acts of emotional, physical or sexual violence in combination) in the past year. $\mathrm{A}^{2} \mathrm{p}$ value was used to test the significance of IPV frequency distribution by risk factors. Adjusted odds ratios (AORs) and 95\% confidence intervals (CIs) from a multiple logistic regression model were used to measure a risk factor in association with IPV, controlling for other risk factors. Clustering sampling effects were adjusted in the logistic regression.

Table 1 Score assignment to questions on women's financial autonomy

\begin{tabular}{lll}
\hline Question & Yes & No \\
\hline $\begin{array}{ll}\text { 1. Are you able to spend the money you earn } \\
\text { as you yourself want? }\end{array}$ & 1
\end{tabular}

2. Do you have to give all or part of the money 1 you earn to your husband?

3. Has your husband ever taken your
earnings/savings or your valuables/other
property from you against your will?

4. Have you ever given up or refused a job for 1 money because your husband did not want you to work?

5. Does your husband ever refuse to give you
money for household expenses, even when
he has the money for other things?


Table 2 Percentage distribution of respondents; and percentage of violence, by variable at individual level ( $n=958)$

\begin{tabular}{|c|c|c|c|c|c|c|c|}
\hline \multirow[b]{2}{*}{ Variables } & \multirow[b]{2}{*}{ n (\%) } & \multicolumn{2}{|c|}{ Emotional violence } & \multicolumn{2}{|c|}{$\begin{array}{l}\text { Physical or sexual } \\
\text { violence }\end{array}$} & \multicolumn{2}{|c|}{ Any violence } \\
\hline & & $\%$ & p Value & $\%$ & p Value & $\%$ & p Value \\
\hline$<30$ & $228(23.8)$ & 16.7 & 0.8081 & 7.0 & 0.2632 & 20.2 & 0.7674 \\
\hline $30 \sim 40$ & 464 (48.4) & 15.1 & & 5.8 & & 17.9 & \\
\hline \multicolumn{8}{|l|}{ Educational level } \\
\hline Primary and lower & $326(34.0)$ & 16.0 & 0.0043 & 9.8 & 0.0483 & 20.9 & 0.0081 \\
\hline Junior & $483(50.4)$ & 12.4 & & 5.6 & & 15.1 & \\
\hline Senior and higher & 149 (15.6) & 23.5 & & 5.4 & & 25.5 & \\
\hline \multicolumn{8}{|l|}{ Age at marriage (years) } \\
\hline High & $59(6.2)$ & 10.2 & 0.5047 & 8.5 & 0.2528 & 13.6 & 0.5007 \\
\hline Medium & $784(81.8)$ & 15.6 & & 6.4 & & 18.8 & \\
\hline Low & $115(12.0)$ & 16.5 & & 10.4 & & 20.8 & \\
\hline \multicolumn{8}{|c|}{ Financial autonomy (score) } \\
\hline 0 (high) & $543(56.7)$ & 14.4 & 0.0004 & $3.0^{\star \star \star}$ & $<0.0001$ & $15.8^{\star \star \star}$ & $<0.0001$ \\
\hline 1 & $283(29.5)$ & 12.0 & & 6.7 & & 15.9 & \\
\hline$\geq 2$ (low) & 132 (13.8) & 26.5 & & 24.2 & & 36.4 & \\
\hline \multicolumn{8}{|c|}{ Job change in the past year } \\
\hline
\end{tabular}

Note: Chi-square-test.

All statistical analysis was performed in SAS version 9.1.3 for Windows (SAS Institute Inc, Cary, North Carolina, USA).

\section{RESULTS}

\section{Characteristics of participants}

The average age of participants and their husbands at interview was $35.4 \pm 6.5$ years and $37.4 \pm 6.7$ years, respectively. Participants were aged 23.0 \pm 2.2 years, on average, at their first marriage. Almost all participants were in their first marriage and had one or more children (98.7\% and $94.5 \%$ respectively, results not shown). Results in tables 2-3 showed that the majority of subjects received junior secondary or lower education $(84.4 \%)$, had medium economic status $(81.8 \%)$, had had no job change in the past year $(95.4 \%)$, agreed that the husband had no reason for hitting his wife $(79.7 \%)$ and did not have a mother or a husband with abused history $(85.7 \%$ and $82.2 \%$, respectively). About a third of respondents $(34.5 \%)$ had lived in Shanghai for $>10$ years and another third $(31.1 \%)$ for $<5$ years (results not shown). More than half of the participants had high financial autonomy $(56.7 \%)$, had relatives in frequent contact and living in Shanghai (57.9\%), and had neighbours to help if needed $(72.8 \%)$. The majority of participants' husbands had a history of drinking but no experience of gambling or physical fight with another man. More than half (57.2\%) were living with their children, $9.5 \%$ living with parents or parents-in-law, and $40.5 \%$ living with husbands only (results not shown). Close to half $(44.5 \%)$ of the participants were self-employed or private owners of businesses, $28.0 \%$ were unskilled workers or workers in service sector (ie, hotels and restaurants, hairdressing and beauty, commerce and social services), $18.5 \%$ were skilled workers or managers and $9 \%$ had had no job recently (results not shown).

About a third $(31.9 \%)$ of participants reported emotional, physical or sexual violence in their married lifetime. Less than one-fifth $(18.7 \%)$ of participants reported any forms of IPV in the past year, with $15.3 \%$ 
Table 3 Percentage distribution of respondents; and percentage of violence, by variable at relationship level $(n=958)$

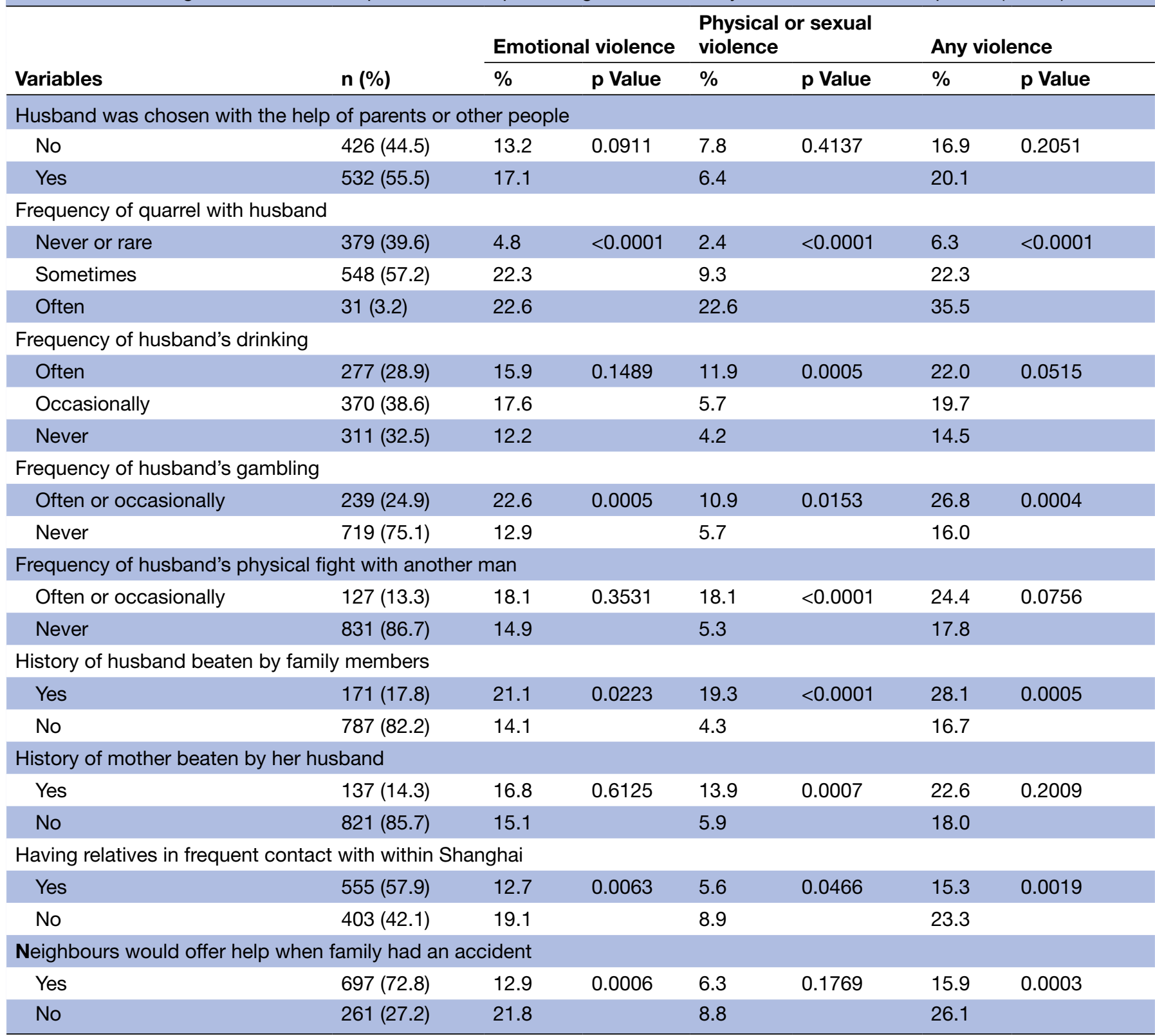

Note: Chi-square-test.

experiencing emotional violence and $7.0 \%$ experiencing physical or sexual violence.

\section{FACTORS ASSOCIATED WITH IPV IN THE PAST YEAR}

Results from bivariate analysis of factors associated with IPV in the past year are shown in tables 2 and 3. Individual factors of women's low financial autonomy, experience of job change in the past year, and agreement that the husband had some reasons for hitting his wife were significantly associated with the three forms of IPV. Higher level of education and being younger at marriage were significantly associated with emotional violence and any violence. Relationship factors of quarrel with husband, having a husband with gambling experience, having a husband with history of abuse by family members and having relatives in frequent contact with within Shanghai were also associated with the three forms of IPV. Having neighbours who would offer help when the family had an accident was significantly associated with emotional violence and any violence, while having a husband with experience of drinking or physical fight with another man, and having a mother with history of abuse by her own husband were only significantly associated with physical or sexual violence.

As shown in table 4, association results from multiple logistic regression were similar to those of the bivariate analysis for emotional violence, except that experience of job change in the past year at individual level was marginally significant $(\mathrm{OR}=2.05,95 \% \mathrm{CI} 0.89$ to 4.72 , $\mathrm{p}=0.0913$ ) and several variables at the relationship level 
Table 4 Multivariable logistic regression model of factors associated with different types of violence, adjusted OR $(95 \% \mathrm{Cl})$ $(n=956)$

\section{Variable}

Emotional violence

Physical or sexual violence Any violence

\section{Individual level}

Age (years)

$\begin{array}{llll}<30 & 1.00 & 1.00 & 1.00 \\ 30 \sim 40 & 0.89(0.49 \text { to } 1.61) & 0.98(0.45 \text { to } 2.13) & 0.80(0.50 \text { to } 1.28) \\ >40 & 0.84(0.50 \text { to } 1.40) & 1.57(0.68 \text { to } 3.60) & 0.90(0.52 \text { to } 1.56)\end{array}$

Education level

\begin{tabular}{|c|c|c|c|}
\hline Primary and lower & 1.00 & 1.00 & 1.00 \\
\hline Junior & $0.72(0.44$ to 1.15$)$ & 0.63 (0.33 to 1.18$)$ & 0.63 (0.41 to 1.13$)$ \\
\hline Senior and higher & $2.29(1.19 \text { to } 4.43)^{\text {t*t* }}$ & 0.74 (0.27 to 2.04$)$ & 1.65 (1.09 to 3.04$)^{* *}$ \\
\hline \multicolumn{4}{|l|}{ Age at marriage (years) } \\
\hline$\leq 22$ & $2.13(1.37 \text { to } 3.31)^{\text {t*t* }}$ & 1.16 (0.61 to 2.05$)$ & $1.71(1.15 \text { to } 2.55)^{\star *}$ \\
\hline$>22$ & 1.00 & 1.00 & 1.00 \\
\hline \multicolumn{4}{|l|}{ Family economic status } \\
\hline High & $1.00(0.32$ to 3.10$)$ & 1.47 (0.36 to 5.96$)$ & $1.13(0.41$ to 3.14$)$ \\
\hline Medium & 1.11 (0.58 to 2.10$)$ & 1.24 (0.56 to 2.74$)$ & 1.21 (0.67 to 2.19$)$ \\
\hline Low & 1.00 & 1.00 & 1.00 \\
\hline \multicolumn{4}{|c|}{ Financial autonomy (score) } \\
\hline 0 (High) & 1.00 & 1.00 & 1.00 \\
\hline 1 & 0.91 (0.55 to 1.49) & 1.85 (0.87 to 3.93$)$ & 1.09 (0.69 to 1.70$)$ \\
\hline$\geq 2$ (Low) & $1.98(1.14 \text { to } 3.42)^{\star *}$ & $7.89(3.86 \text { to } 16.14)^{* * *}$ & $2.84(1.71 \text { to } 4.70)^{* * *}$ \\
\hline \multicolumn{4}{|c|}{ Job change in the past year } \\
\hline Yes & 2.05 (0.89 to 4.72$)$ & $4.03(1.57 \text { to } 10.35)^{* *}$ & $2.82(1.30 \text { to } 6.12)^{* *}$ \\
\hline No & 1.00 & 1.00 & 1.00 \\
\hline
\end{tabular}

Reasons for husband hitting wife

$\begin{array}{llll}\text { None } & 1.00 & 1.00 & 1.00 \\ \text { Any } & 1.96(1.22 \text { to } 3.14)^{* *} & 1.65(0.85 \text { to } 3.19) & 1.71(1.10 \text { to } 2.66)^{*}\end{array}$

\section{Relationship level}

Husband was chosen with the help of parents or other people

$\begin{array}{llll}\text { No } & 1.00 & 1.00 & 1.00 \\ \text { Yes } & 1.19(0.76 \text { to } 1.86) & 0.54(0.29 \text { to } 1.04) & 1.07(0.71 \text { to } 1.62)\end{array}$

Frequency of quarrel with husband

$\begin{array}{llll}\text { Rarely } & 1.00 & 1.00 & 1.00 \\ \text { Sometimes } & 7.14(4.22 \text { to } 13.02)^{*} & 2.06(0.93 \text { to } 4.55) & 6.04 \text { (3.65 to } 9.98)^{* *} \\ \text { Often } & 6.23(2.09 \text { to } 18.62)^{* *} & 2.28(0.63 \text { to } 8.35) & 7.07(2.71 \text { to } 18.45)^{*}\end{array}$

Frequency of husband's drinking

$\begin{array}{llll}\text { Often } & 0.91(0.52 \text { to } 1.58) & 1.98(0.91 \text { to } 4.31) & 1.19(0.72 \text { to } 1.97) \\ \text { Occasionally } & 1.03(0.62 \text { to } 1.70) & 1.03(0.46 \text { to } 2.31) & 1.02 \text { (0.63 to } 1.63) \\ \text { Never } & 1.00 & 1.00 & 1.00\end{array}$

Frequency of husband's gambling

$\begin{array}{llll}\text { Ever } & 1.37(0.89 \text { to } 2.19) & 0.91(0.47 \text { to } 1.76) & 1.29 \text { (0.84 to } 1.98) \\ \text { Never } & 1.00 & 1.00 & 1.00\end{array}$

Frequency of husband's physical fight with another man

$\begin{array}{llll}\text { Ever } & 0.65(0.35 \text { to } 1.22) & 1.87(0.93 \text { to } 3.76) & 0.71 \text { (0.40 to } 1.25) \\ \text { Never } & 1.00 & 1.00 & 1.00\end{array}$


Table 4 Continued

\begin{tabular}{|c|c|c|c|}
\hline Variable & Emotional violence & Physical or sexual violence & Any violence \\
\hline \multicolumn{4}{|c|}{ History of husband beaten by family members } \\
\hline Yes & $1.45(0.86$ to 2.44$)$ & $4.67(2.17 \text { to } 7.69)^{\star \star *}$ & $1.20(1.06 \text { to } 2.72)^{*}$ \\
\hline \multicolumn{4}{|c|}{ History of mother beaten by her husband } \\
\hline Yes & $0.91(0.51$ to 1.60$)$ & 1.85 (0.95 to 3.64$)$ & $1.03(0.62$ to 1.73$)$ \\
\hline \multicolumn{4}{|c|}{ Having relatives in frequent contact with within Shanghai } \\
\hline Yes & $0.62(0.40 \text { to } 0.94)^{*}$ & $0.97(0.53$ to 1.80$)$ & $0.62(0.42 \text { to } 0.92)^{\star}$ \\
\hline No & 1.00 & 1.00 & 1.00 \\
\hline \multicolumn{4}{|c|}{ Neighbours would offer help when family had an accident } \\
\hline Yes & 1.00 & 1.00 & 1.00 \\
\hline
\end{tabular}

Note: ${ }^{*} p<0.05,{ }^{* *} p<0.01,{ }^{* * *} p<0.0001$.

were no longer statistically significant, including having a husband with gambling experience, having neighbours to help with a family accident and having a husband with history of physical abuse by family members. For physical or sexual violence, individual factors of low financial autonomy and experience of job change in the past year, and relationship factor of having a husband with abused history remained strong risk factors in the multiple analysis. Husband's experience of physical fight with another man $(\mathrm{OR}=1.87,95 \% \mathrm{CI} 0.93$ to $3.76, \mathrm{p}=0.0809)$ and having a mother with abused history by her own husband $(\mathrm{OR}=1.85,95 \%$ CI 0.95 to $3.64, \mathrm{p}=0.0725)$ were only marginally significantly associated with physical or sexual violence. Whereas frequency of quarrel with husband, husband's experience of drinking, husband's experience of gambling, having relatives in frequent contact with within Shanghai or having neighbours to help at a family accident were no longer statistically significantly associated with respondents' experience of physical or sexual violence. For any violence, results from multiple regression were similar to those from bivariate analysis, except that having a husband with gambling experience and having neighbours to help at a family accident were no longer statistically significant.

\section{DISCUSSION}

To the best of our knowledge, this is the first study to assess IPV and possible risk factors associated with different types of IPV among rural migrant women in China. The modified study method was adopted from the WHO Multi-country Study on Women's Health and Domestic Violence against Women ${ }^{24}$ to measure IPV and related factors, which enables international comparability and ensures high quality of the data. For example, the definitions of violence used a range of behaviour-specific questions related to each type of violence, which have been widely employed in studies of partner violence in the United States and elsewhere, and have been shown to encourage greater disclosure of violence than approaches that require respondents to identify themselves as abused or battered. ${ }^{26}{ }^{27}$ Findings from this study show that several risk factors for IPV at individual and relationship levels among married rural migrant women in China are consistent with existing evidence among non-migrant women in China and other countries, ${ }^{45-11}$ including young age at marriage, low financial autonomy, acceptance of wife beating by husband, low relationship quality and history of husband beaten by family members. Additional factors associated with IPV among rural migrant women identified in this study were a job change in the past year and having relatives in frequent contact with within Shanghai. While some risk factors were unique to a particular type of violence, common risk factors were shared by various types of violence in this study, which is consistent with studies from other countries. ${ }^{3} 28$

At the individual level, numerous studies have identified that low level of education is a risk factor of IPV. ${ }^{2}{ }^{29-32}$ However, we failed to identify such a relationship with physical or sexual violence in our study, possibly owing to the small sample size of women with physical or sexual abuse. In contrast, this study found that a higher level of education was strongly associated with an increased risk of emotional violence. There is a proverb in China that a male should reason thing out rather than resort to force. Husbands with higher education may therefore think that it is beneath their dignity to use force to deal with conflict or resolve disagreement. In addition, emotional abuse may be less likely to be perceived as a form of violence in comparison with physical or sexual abuse. As a result, emotional violence rather than physical or sexual violence is more likely to be perpetrated against a wife by a husband with higher level of education in China. A previous study also found that women with a higher level of education than their husbands were 
at increased risk for IPV. ${ }^{933-35}$ This study confirmed this finding for physical or sexual violence $(12.8 \%$ vs $6.5 \%$, $\left.{ }^{2}=4.4321, \mathrm{p}=0.0353\right)$ but not emotional violence $(10.3 \%$ vs $\left.15.8 \%,{ }^{2}=1.6923, \mathrm{p}=0.1933\right)$.

Beside women's education level, individual factors of financial autonomy and job change in the past year were also strongly associated with IPV. Women with low financial autonomy and a job change in the past year were significantly more likely to report IPV. However, family economic status was not a predictor of IPV. These findings suggest that economic inequality in a relationship is a more important predictor of IPV than family economic status.

Unexpectedly, this study did not find that women's age was associated with IPV, which is in line with findings from studies in China ${ }^{911}$ but differs from studies in other countries, including the WHO multi-country study. ${ }^{4529-32} 36$ Most studies in China were conducted in married women aged between 31 and 36 years, on average, excluding younger women of aged $<20$ years, which might have led to the null association of women's age with IPV. More studies are therefore needed to confirm this null association.

This study found strong associations of relationship factors of quarrelling with husband and history of husband being beaten by a family member with IPV but weak association between support from relatives or neighbours and IPV. High marital conflicts and partner's behaviours, such as drug use, harmful use of alcohol and fighting with other men, in a partnership are other commonly cited risk factors at relationship level associated with women's experience of IPV. ${ }^{457}$ This study did find that a husband's experience of drinking or physical fight with another man were associated with physical or sexual violence, but the results were only significant in the bivariate analysis not the multiple regression analysis. The small sample size of women with physical or sexual violence might have contributed to the change of statistical significance.

Several limitations of the study must be mentioned. First, some women might have chosen not to disclose IPV, especially physical or sexual violence because this is generally considered an embarrassing private matter in China, even though this study used a methodology that considerably improved the disclosure of IPV and quality of data. Second, this study has insufficient statistical power to examine some variables in association with IPV (such as, partner's behaviours and physical or sexual violence) owing to small sample size. Third, this study did not collect scaled data on family economic status. Because of the homogeneity of family economic status among respondents, this study failed to identify significant associations between family economic status and IPV. Finally, results from this cross-sectional study could provide evidence only for associations but not for causality.

Despite these limitations, the study findings have public health implications for the primary prevention of IPV. The identified risk factors highlight the need for comprehensive interventions to deal with IPV among migrants at various levels. The interventions should focus on improving financial autonomy and employment status of women, promoting problem-solving and interaction skills of the couples, and changing their knowledge or attitudes towards gender norms and IPV.

At individual level, interventions should provide training on occupational skills for migrants, provide them with equal opportunities and rights to the local urban residence in the area of employment, payment, social security and public services, increase migrant women's economic and social power, and change their attitudes towards social and culture norms related to gender that support IPV.

At relationship level, efforts should be made to promote problem-solving and interaction skills and to reduce behaviours leading to marital conflicts in order to reduce quarrels between couples.

In addition, to change individual's attitudes and behaviours, a supportive environment at community and societal levels is also needed based on the ecological model. On 27 December 2015, China's top legislature passed the country's first law against domestic violence in a landmark move to bring traditionally silent abuse victims under legal protection. ${ }^{38}$ The new law defines domestic violence as "physical, psychological and other harm inflicted by family members with beatings, restraint or forcible limits on physical liberty, recurring invectives and verbal threats'. With it coming into force in March 2016, domestic violence will no longer be a 'family matter' but a legal issue that demands action from the court and police. While the new law may deal with the law enforcement side of the problem, changing people's attitudes toward domestic violence is still the fundamental challenge in China. Public education programmes should be carried out by government departments, communities, schools, medical institutions, women's associations and other social groups.

Acknowledgements We thank the local Population and Family Planning Committee for their support in the field work. We also gratefully acknowledge Dr Juan Yang from the outcomes and long-term follow-up section, Genetic Disease Screening programme, California Department of Public Health, who helped us to improve the quality of the article.

Contributors XT led study design, acquisition of data, analysis and interpretation of data, and drafting and revising the article. CL involved in design of the work, acquisition of data, interpretation of data, and revising the article.

Funding The study on which this article is based was supported by the Ford Foundation.

Competing interests None declared.

Ethics approval the Institutional Review Board of the Shanghai Institute of Planned Parenthood Research, Shanghai, China.

Provenance and peer review Not commissioned; externally peer reviewed.

Data sharing statement No additional data are available.

Open Access This is an Open Access article distributed in accordance with the Creative Commons Attribution Non Commercial (CC BY-NC 4.0) license, which permits others to distribute, remix, adapt, build upon this work non-commercially, and license their derivative works on different terms, provided the original work is properly cited and the use is non-commercial. See: http://creativecommons.org/ licenses/by-nc/4.0/ 
(C) Article author(s) (or their employer(s) unless otherwise stated in the text of the article) 2017. All rights reserved. No commercial use is permitted unless otherwise expressly granted.

\section{REFERENCES}

1. United Nations. Ending violence against women: from words to action. New York: United Nations, 2006:43-5. http://www.un.org/ womenwatch/daw/public/VAW_Study/VAWstudyE.pdf (accessed 22 March 2015).

2. Heise L. What works to prevent partner violence? An evidence overview. London: Department for International Development, 2011:1-9.

3. Fulu E, Jewkes R, Roselli T, et al; UN Multi-country Cross-sectional Study on Men and Violence research team. Prevalence of and factors associated with male perpetration of intimate partner violence: findings from the UN Multi-country Cross-sectional study on men and violence in Asia and the Pacific. Lancet Glob Health 2013;1:e187-e207.

4. World Health Organization/London School of Hygiene and Tropical Medicine. Preventing intimate partner and sexual violence against women: taking action and generating evidence. Geneva: World Health Organization, 2010:5-33.

5. Capaldi DM, Knoble NB, Shortt JW, et al. A systematic review of risk factors for intimate partner violence. Partner Abuse 2012;3:231-80.

6. Parish WL, Wang T, Laumann EO, et al. Intimate partner violence in China: national prevalence, risk factors and associated health problems. Int Fam Plan Perspect 2004;30:174-81.

7. Tang CS-K, Lai BP-Y. A review of empirical literature on the prevalence and risk markers of male-on-female intimate partner violence in contemporary China, 1987-2006. Aggress Violent Behav 2008;13:10-28.

8. Chan KL, Brownridge DA, Tiwari A, et al. Understanding violence against Chinese women in Hong Kong: an analysis of risk factors with a special emphasis on the role of in-law conflict. Violence Against Women 2008;14:1295-312.

9. Xu X, Zhu F, O'Campo P, et al. Prevalence of and risk factors for intimate partner violence in China. Am J Public Health 2005;95:78-85.

10. Guo SF, Wu JL, Qu CY, et al. Domestic violence against women before, during and after pregnancy. Zhonghua Liu Xing Bing Xue Za Zhi 2004;25:9-11. (in Chinese).

11. Guo SF, Zhao FL, JI W, et al. Study on prevalence of domestic violence and its related factors in rural area of China. China Public Health 2007;23:4-6. (in Chinese).

12. National Bureau of Statistics of China. Statistical communiqué of the people's Republic of China on the 2014 National Economic and Social Development. http://www.stats.gov.cn/enGliSH/PressRelease/ 201502/t20150228_687439.html (accessed 2 December 2015).

13. The floating population division of national health and family planning commission. The development report on China's Migrant Population. 2014 http://www.nhfpc.gov.cn/xcs/s3574/201411/ dc3ba043cbf74e2d8fe68000d4651505.shtml (accessed 10 April 2015).

14. Keung Wong DF, Li CY, Song HX. Rural migrant workers in urban China: living a marginalised life. Int J Soc Welf 2007;16:32-40.

15. Chen Y. Rural migrants in urban China: characteristics and challenges to public policy. Local Economy 2011;26:325-36.

16. Shi L, Rural migrant workers in China: scenario, challenges and public policy (Working paper No. 89). International labour office, policy integration and statistics department. Geneva ILO 2008:6-17.

17. Wu X, Treiman DJ. The household registration system and social stratification in China: 1955-1996. Demography 2004;41:363-84.
18. Cai Q. Migrant remittances and family ties: a case study in China. International Journal of Population Geography 2003;9:471-83.

19. Han K-Q, Huang C-C, Han W-J. Social mobility of migrant peasant workers in China. Sociology Mind 2011;01:206-11.

20. Tu X, Lou C, Sun F, et al. [Situation of domestic violence and health outcomes among married migrant women at reproductive age]. Zhonghua Liu Xing Bing Xue Za Zhi 2014;35:484-8. (in Chinese).

21. Tu X, Lou C, Sun F, et al. Patterns of domestic violence among married migrant women of reproductive age and its relationship with abnormal pregnancy outcomes in Shanghai. Sheng Zhi Yu Bi Yun 2014;34:295-300. (in Chinese).

22. Shanghai Municipal Bureau of Statistics. Shanghai sixth national census in 2010 communiqué on major data. http://www.shanghai. gov.cn/shanghai/ node2314/node2319/node12344/ u26ai25463.html (accessed 14 April 2015).

23. Department of Family Development, National Health and Family Planning Commission. China Family Development Report 2015. Beijing. China Population Publishing House, 2015:10-11. (in Chinese).

24. Garcia-Moreno C, Jansen HA, Ellsberg M, et al. WHO Multi-country Study on Women's Health and Domestic Violence against Women. Geneva: World Health Organization, 2005:27-42.

25. World Health Organization. Putting women first: ethical and safety recommendations for research on domestic violence against women (WHO/FCH/GWH/01.1). Geneva: World Health Organization, 2001:9-29.

26. Krug EG, Dahlberg LL, Mercy JA, et al. World report on violence and health. Geneva: World Health Organization, 2002:91-3.

27. Ellsberg MC, Heise L. Researching violence against women: a practical guide for researchers and activists. Washington, DC: PATH/ World Health Organization, 2005:85-101.

28. Ali TS, Asad N, Mogren I, et al. Intimate partner violence in urban Pakistan: prevalence, frequency, and risk factors. Int $J$ Womens Health 2011;3:105-15.

29. Thompson RS, Bonomi AE, Anderson M, et al. Intimate partner violence: prevalence, types, and chronicity in adult women. Am J Prev Med 2006;30:446-57.

30. Kouyoumdjian FG, Calzavara LM, Bondy SJ, et al. Risk factors for intimate partner violence in women in the Rakai community cohort study, Uganda, from 2000 to 2009. BMC Public Health 2013;13:566.

31. Abramsky T, Watts $\mathrm{CH}$, Garcia-Moreno $\mathrm{C}$, et al. What factors are associated with recent intimate partner violence? Findings from the WHO multi-country study on women's health and domestic violence. BMC Public Health 2011;11:109.

32. Stöckl H, March L, Pallitto C, et al; WHO Multi-country Study Team. Intimate partner violence among adolescents and young women: prevalence and associated factors in nine countries: a crosssectional study. BMC Public Health 2014;14:751.

33. Flake DF, Individual FDF. Individual, family, and community risk markers for domestic violence in Peru. Violence Against Women 2005;11:353-73.

34. Ackerson LK, Kawachi I, Barbeau EM, et al. Effects of individual and proximate educational context on intimate partner violence: a population-based study of women in India. Am J Public Health 2008;98:507-14.

35. Ko Ling Chan. Sexual violence against women and children in Chinese societies. Trauma Violence Abuse 2009;10:69-85.

36. Cohen MM, Maclean H. Violence against canadian women. BMC Womens Health 2004;4 Suppl 1:S22.

37. Djikanovic B, Jansen HA, Otasevic S. Factors associated with intimate partner violence against women in Serbia: a cross-sectional study. J Epidemiol Community Health 2010;64:728-35.

38. Yang Y. China's first law against domestic violence to protect wives. http://www.womenofchina.cn/womenofchina/html1/features/rights/ 1601/42-1.htm (accessed 18 January 2016). 